\title{
The Configuration of Salsa Masculinities on Salsaforums.com
}

\author{
WANG Qiong \\ Guangdong University of Foreign Studies, Guangzhou, China
}

\begin{abstract}
This essay examines the configuration of masculinities in salsa dance based on discussions on a popular salsa website, Salsaforums.com. With a thorough combing of the popular threads on male dancers, it contends that in the traditional framework of performance of men in salsa, the issue of masculinity as a social practice embedded in the discursive structuring of various social forces has to be explored from a dynamic and eclectic perspective. Discourses are manifest in the male dancers' pride, insecurity, and anxiety. While trying to retain dispositions or attributes traditionally ascribed to men, however, male salsa dancers are negotiating a salsa masculinity that is multiple, fluid, flexible, and on the way to embrace a more inclusive spectrum of possibilities.
\end{abstract}

Keywords: hegemonic masculinities; embodied experience; inclusive masculinities

\section{Introduction}

This essay examines the configuration of masculinities in salsa dance based on discussions on a popular salsa website, Salsaforums.com ${ }^{1}$. This US-based website is the hottest forum for salsa dance information, gatherings, instructions, etc., which covers topics from dance instructions, rules, tips, to gender and social issues involved in salsa. Salsa is a partnered social dance with Latin origin, in which the dancers (usually a man and a woman) perform the dance in a lead-follow fashion where sex roles are more strictly defined and observed compared to other forms of social leisure activities. Men taking the lead while women follow designates a traditional pattern of the male-female dichotomy, with men being seemingly in a dominant position in the social stratum. The dance itself, however, compromises the power embedded in this fashion, as dance has always been categorized as a feminized social activity (Gard, 2006, p. 9). From the popular threads on Salsaforums.com, the well-defined classification of sex roles has not promised a secure sense of masculinity for male dancers. Insecurity and anxiety are frequently spotted in such discussions as "hip movement question", "is salsa becoming more effeminate", "should male follower be masculine or feminine", or "what do women think of men who dance salsa". With a thorough combing of the popular threads on male dancers, this essay contends that in the traditional framework of performance of men in salsa, the issue of masculinity as a social practice embedded in the discursive structuring of various social forces has to be explored from a dynamic and eclectic perspective. Discourses are manifest in the male dancers' pride, insecurity, and anxiety. While trying to retain dispositions or attributes traditionally ascribed to men, however, male salsa dancers are negotiating a

\footnotetext{
WANG Qiong, MA in Literary and Culture Studies, Lecturer, Guangdong University of Foreign Studies, Guangzhou, China. ${ }^{1} \mathrm{https}: / /$ www.salsaforums.com. The texts are entirely extracted from this website, mainly focusing on the following threads: What do women think of men who dance; Is salsa becoming more effeminate; The decline of salsa in NYC; Should Male followers be masculine of feminine; Hip movement question; Dancing with the same sex; Dancing to show off; Men's vs. lady's styling; Leaders' blacklist; Sexism in dance; Should male follower be masculine or feminine; Femininity in salsa dancing; Top ten things guys don't do on the dance floor; Rules of salsa dance floor; Dance etiquette; Four ways to be a really good leader and excellent dancer; Essential steps to get that "Yes", etc.
} 
salsa masculinity that is multiple, fluid, flexible, and on the way to embrace a more inclusive spectrum of possibilities.

The term "configuration" is stemmed from R. W. Connell's discussion of masculinity, which involves "the process of configuring practice" that hinges on the body, and its interaction with others and operation in the social structure (Connell, 2005, p. 72). The corporeal/the performative, and the structures of power relation (notably the patriarchal hierarchy in the gendered relations) have been the two main concerns of the study of masculinity in the rich scholarship in the past two or three decades. Connell argues that there is no "fixed" or "true" masculinity in men as a whole (Connell, 2005, p. 45). Masculinity "is simultaneously a place in gender relations, the practices through which men and women engage that place in gender, and the effects of these practices in bodily experience, personality and culture" (Connell, 2005, p. 71). With the body as both the object and agent of social practice, which in turn forms the structures that define and appropriate the body, Connell (2005, p. 61) proposes a pattern of their interaction as body-reflexive practice. Masculinity as dispositions or performance attached to the male body is closely linked with its experience, as the pattern suggests, through which one learns "how to be both in his body...and outside his body watching its gendered performance" (Connell, 2005, pp. 62-63). Hence masculinities should be the object of study. Scholars like Kevin Floyd and Stefan Horlacher $(2017$, p. 1) acknowledge the plural nature of the term, but argue that the plurality has to be addressed on the basis of commonalities shared in masculinities. Connell's discussion of four types of masculinities very well places the commonalities under the plurality of the term. The configuration of salsa masculinities, therefore, will be framed under Connell's pattern of body-reflexive practice, which incorporates the dancers' embodied experience (in the body), the expectations of "the masculine" as a result of social construction and discipline (outside the body), and the understanding of the notion and the consequent strategy contoured through affirmation or negation derived from their encounter with the glorified or stigmatized (effects of the practice).

\section{Expectations of Masculinity}

One characteristic of a good salsa dancer is power....As a leader, you want your partner to dance the right move at the right time, you don't want her to do something completely different, do you?... Control means being in control of yourself and your partner....Just like driving a car, you want to make sure that you have control of the situation...Y You want your dancing to be like the driving in the Fast \& Furious or Mission Impossible movies.

- Anya Brodech, Salsa Teacher

Women teachers used to menacingly pace up and down the aisles and go "LADIES... the GUYS are in CHARGE of the dance. YOU are not in charge. IT IS YOUR JOB to FOLLOW ladies... The power needs to come from you. LEAD HER. Yes or YES?"

- Chris-Yannick, Dancer

Brodech, a professional salsa dancer and teacher from California, in her thread " 4 Ways to Be a Really Good Leader and Amazing Salsa Dancer" gives guidance to salsa leaders epitomized in four words: power, control, speed, and precision, of which "power" is the core. Instructions like this are frequently heard in classroom teaching. Male dancers are by default the leader, as they are bestowed the role. Sex role theory attaches the roles of men and women to their biological body, and despite the critique on its essentialist basis, it legitimizes asocial construction imprinted in various domains. Connell points out the possible mis-perception 
of social reality by reducing sex roles to base on two homogeneous dichotomies, yet he admits that "the dramaturgical metaphor of role" functions and is apt for a well-defined, well-scripted, and low-risk situation with a willing audience like social partnered dance (Connell, 2005, p. 26). "Power", "control", "drive", "in charge", all fall into Connell's description of hegemonic masculinities, i.e. the acknowledged answer to the problem of the legitimacy of patriarchy "which guarantees the dominant position of men and the subordination of women" (Connell, 2005, p. 77). This culturally exalted expectation of masculinity may not always be within the reach of ordinary men, but it has visible bearers, or exemplars, like stars in films. The quoted salsa teacher employs the images of masculine heroes in The Fast \& Furious or Mission Impossible to indicate the male dancers' dramaturgical role in the dance floor, where they have to exhibit what justifies them as the dominant sex.

Like their peers studied in salsa literature, dancers at Salsaforums.com welcome a masculine leader that is capable of making decisions. In threads like "Decline of NYC Salsa", or "Leading vs. Following", the claim that it's essential to have a masculine leader has drawn many posts of consent. Some attribute the decline of salsa in New York to the fact that salsa leaders are less assertive, less aggressive with less raw, masculine energy. The configuration and acceptance of the hegemonic part of masculinities in salsa literature is justified by its dramaturgical implication and the detachment of personal value and belief of sex roles from the "sexist" role-playing (Beggan \& Pruitt, 2014, p. 510). The posts on the forum discuss the necessity of "raw" masculine types under similar frame of reference. Though most female dancers explicitly reject male dominance in real life, they have no problem dancing in the male-dominant role setting of salsa. Political correctness can be disregarded, as this gendered pattern is secured in a specific time and space with the dramaturgical metaphor granting the license. One of the dancers complains about the perception that may compromise the dance by challenging the traditional role assignment, "It's not about trying to look the part, it's about being. Salsa is... a partner dance and a social activity... (No matter) how progressive Europeans and others try to mold it to accommodate their own second hand and skewed perception of the dance, you wouldn't expect a lead to look soft".

With a substantial part of the hegemonic masculinity preferred in the leading role, the instructions also offer tricks to win the favor of ladies. Many of the "rules", "etiquette", "mistakes to avoid" etc. continue the classroom teaching by modifying certain aspects of masculine behaviors. Male dancers are expected to be clean, gentle, protective, and understanding, which are deemed to go with the code of gentry. This line of traits forms part of what Connell describes as complicity masculinities, which induce a less offensive male figure than the hegemonic type. They are constructed not to embody, but benefit from hegemonic masculinities (Connell, 2005, p. 79). If hegemonic masculinity means also violence, rudeness, apathy, or despise of the weak on top of the strong and heroic image that keeps things under control, complicity masculinity in a way offsets its negative connotations. A refined vision of salsa masculinity is provided by ladies, "All the leads I have ever enjoyed watching look very masculine. But they don't necessarily look like the macho man, alpha male type. It's more subtle than that... Because masculinity should not necessarily be offensive and/or ignorant, rather tempered with knowledge, experience and empathy for the lady". By patronizing the female counterpart on the dance floor, the male dancers reinforce male dominance in a subtle manner, portraying female dancers as the weaker ones and men as the initiator of activities. 


\section{Embodied Experience, Insecurity, and Anxiety}

I'm asking b/c sometimes I am a bit apprehensive about letting people know about this "other" life I live in the dance floor...I'm afraid of putting my masculinity on the line.

- Peachexploration, Dancer

I remember when I first started dancing salsa, I told a friend what I was doing. The first thing out of her mouth was "Aren't all the men gay?" ...being a dancer may not score you high on other peoples "masculinity scale".

- Lolita, Dancer

The dramaturgical practice of masculinities in salsa dance projects a confusing experience of the body. Performing the role as traditionally ascribed to men explains the conformity to the rigid role assignment in salsa dance. Performance through repetitive practice, however, also means a process of corporeal inscription. The classroom teaching, peer communication, and group consensus form part of the discourse that regulates and delineates the male dancers' reflection of their own embodied experience of salsa. They partake the somatic training, analyze dancing techniques, and practice bodily movements, through which the materiality of their body goes beyond the mere role-play, and intertwines with their self-identification as a man.

With its role-setting that highlights the male dominance, salsa basically involves the expressive characteristic of dance that is heavily associated with femininity (Risner, 2009, p. 8). Connell relates the subordination masculinities to the European and American culture where the masculine hierarchy is established on the repellence of assimilation with femininity, including homosexuality (Connell, 2005, p. 78). The association of homosexuality with femininity is based on the prescription of binary sexual relationship. If one man is in a sexual relationship with another man, one of them has to assume a female role. Therefore, the orthodox reaction to this category is assigned tenets of homophobia and anti-femininity (Anderson, 2009, p. 31). In threads titled "What do women think of men who dance", or "Is Salsa Becoming More Effeminate", male dancers expressed their concern far more seriously than their female counterparts. Their insecurity comes from the slippery towards the subordination type, "putting the masculinity on the line and not scoring high on the masculinity scale", because the dance associates their body with the feminine and/or homosexual end of the gender spectrum.

The embodied experience as reflected in body movements accentuates the male dancers' anxiety over a boundary of masculinity. One of the threads deals with hip movement. The speaker finds that "many guys...are afraid that they will look feminine (or ...be seen as 'gay') if they move their hips". Despite a salsa teacher's post that says "The fact that you move your hips and shoulders while you dance doesn't automatically transform you into a gender that you're not", most of the posts rest on the techniques of body movement, the style, and to what degree can a male dancer move his hip without being viewed as sissy or gay. The discussion revolves around finding a plausible boundary for the safe display of the male body, with a consensus that hip movement manifests so much femininity that only the highly skilled male dancers can use it in a masculine way. In this context, prowess, the skills, compensates to offset the feminine connotations of the hip movement. For the less skilled, several posts offer their suggestion of more "manly" or macho Afro-Cuban dances where there's a lot of shoulder/torso usage. Traditionally, the usage of hip, or some other body parts having to do with sexuality in dance is mostly accredited to female dancers, as these are deemed of gaze value. Compared to women who have been for ages the object of gaze, men, as Mulvey argues, "cannot bear the burden of sexual objectification" 
(Mulvey, 1975, p. 838). Torso and shoulder direct to strength and macho power, while hip movements would diminish the masculine identification.

There is a mixed understanding of Latin and black male dancers. The Latin and the black, whose dance vocabulary of hip movements and torso undulations renders them the "low" and "primitive" originators of salsa (Pietrobruno, 2006, p. 78; Hanna, 2010, p. 224), seem to fit Connell's marginalized type of masculinities constructed as a result of the institutional oppression of the socially and racially less privileged and marginalized (Connell, 2005, p. 80). They are deemed emotional, unorganized, and pleasure-seeking (Desmond, 1994, p. 50). On Salsaforums.com, myth about their natural gift of dancing and their raw, aggressive machismo are surprisingly welcome. White dancers envy their popularity on the dance floor, though the colonial conception of the Latin as "sensual", "primitive", and "not serious" often finds its traces on the posts. The Latin and the black move their hips in a way that does not allude to femininity for two reasons: the attribution of their movement to the "natural racial character" as "they are born with that" and their more severe attitude towards homosexuality. One female Latin dancer remarks that "(the Latino male dancers) are very manly, have a lot of pride as a man and in their culture dancing has nothing to do with being gay. And for Latino males being associated with being gay is one of the worst things, it is a stigma". The repulsion of homosexuality reinforces Latino men's masculinity, and one of the male dancers has the Latinos in mind when he says "I wish Salsa would go back to being rougher, tougher, more rhythmic, more masculine, more aboriginal, more pro-man".

\section{Inclusive Masculinities}

Men's insecurity and anxiety are seen by masculinity scholars as the costs associated with hegemonic masculinities, which necessitates that one perpetuates the goal-chasing that will never accomplish. Anderson adds to the costs the concern of all the variables like class, race, or good looks, suggesting that in recent decades the changes of gender studies and practices have brought about a decreasing of social stigma and institutional control of the less orthodox views. He proposes the concept "inclusive masculinity" to refer to the changing nature of masculinities, which embraces "the equal inclusion of gay men as it is about the inclusion of straight men's femininity" (Anderson, 2009, p. 9). Dancers on Salsaforums.com articulate their response to most masculinity issues in this regard. Many describe the nature of salsa dace with "expression", the artistic value as well as purpose that will "free the mind and body without being constricted or scripted". Teachers and dancers agree on the basic function of the dance as enjoyment, "it doesn't matter whether it looks masculine or feminine, as long as the movement is controlled and expressive and musical". Parsons talks about expressive interests in art that purport to "'act out' the need-disposition itself rather than subordinating gratification to the goal outside the immediate situation or to a restrictive norm" (Tanner, 2003, pp. 233-234). This is resounded in his distinction of sex roles in small social groups like a family, where women assume the "expressive" role while men play the "instrumental" role (Parsons \& Bale, 1955). The expressive is associated with the cathexis of the actor, which reaffirms the connection between certain traits of femininity with the artistic, or the freedom and purity the dance promises. By advocating a focus on the expressive aspect of salsa, dancers are open to a less rigid distinction of the masculine and the feminine, and with inclusive masculinity, one expects to take the expressive side of men more naturally. The word "fluidity" goes through several threads, which indicates tolerance and inclusion, a metaphor of both the attitude and the practice of the dancers in dancing as well as in real life. 


\section{Conclusion}

The issue of masculinity on Salsaforums.com roughly contours a salsa masculinity at work. With its lead-follow tradition maintained by classroom instructions and party practices, its containment of hegemony masculinities observed by most dancers, and its performing properties, the mainstream notion of masculinity is still prominent. The hegemony of a homophobic and misogynistic masculine culture finds its cost in the realm of salsa manifested by the insecurity and anxiety of male dancers in their masculine identity. Equally present are the mixed understanding of the racially marginalized male, and the inclusion of an alternative masculinity that practices greater equality between the two sexes. With the social and cultural changes and the dynamic interaction of people and space, salsa masculinity is configurated as a result of the diversified discourses that are changing as well.

\section{References}

Anderson, E. (2009). Inclusive masculinity: The changing nature of masculinities. New York \& London: Routledge.

Beggan, J. K., \& Pruitt, A. S. (2014). Leading, following and sexism in social dance: Change of meaning as contained secondary adjustments. Leisure Studies, 33(5), 508-532.

Connell, R. W. (2005). Masculinities. Berkeley, CA: University of California Press.

Desmond. J. C. (1994). Embodying difference: Issues in dance and cultural studies. Cultural Critique, 26, 33-63.

Gard, M. (2006). Men who dance: Aesthetics, athletics and the art of masculinity. New York: Peter Lang Publishers.

Hanna, J. L. (2010). Dance and sexuality: Many moves. The Journal of Sex Research, 47(2-3), 212-241.

Horlacher, S., \& Floyd, K. 2017. Contemporary masculinities in the UK and the US: Between bodies and systems. New York: Springer International Publishing.

Mulvey, L. (1975/1999). Visual pleasure and narrative cinema. In L. Braudy and M. Cohen (Eds.), Film theory and criticism: Introductory readings (pp. 833-844), 5th ed. Oxford: Oxford University.

Parsons, T. (2003). Art as expressive symbolism: Action theory and the sociology of art. In J. Tanner (Ed.), The sociology of art: A reader. London: Routledge.

Pietrobruno, S. (2006). Salsa and its transnational moves. Lanham, MD: Lexington Books.

Risner, D. (2009). What we know about boys who dance: The Limitations of contemporary masculinity and dance education. In J. Fisher and A. Shay (Eds.), When men dance: Choreographing masculinities across borders. Oxford: Oxford University Press. 